\title{
O corpo afrodescendente e a escola: narrativas pessoais como possibilidades de
}

\section{superação do racismo}

The Afro-descendant body and the school: personal narratives as possibilities for overcoming racism

El cuerpo afrodescendiente y la escuela: narrativas personales como posibilidades de superación del racismo

\author{
Kácio dos Santos Silva \\ ORCID: https://orcid.org/0000-0003-1577-0270 \\ Universidade Estadual do Piauí, Brasil \\ Centro Universitário Santo Agostinho, Brasil \\ kaciosantos@frn.uespi.br \\ Francis Musa Boakari \\ ORCID: https://orcid.org/0000-0002-5786-2387 \\ Universidade Federal do Piauí, Brasil \\ musabuakei@yahoo.com
}

\begin{abstract}
Resumo
O presente estudo refere-se às relações do corpo afrodescendente com a escola, com o objetivo de compreender como a escola pode contribuir no processo de valorização dos diferentes corpos na intenção de combater o racismo. Sabe-se que o racismo no decorrer da história de formação do povo brasileiro deixou grandes sequelas sociais e com isso pretende-se além de denunciar, propor possibilidades de enfrentamento do mesmo. Como metodologia, a pesquisa optou por seguir a perspectiva da revisão narrativa, que busca referenciais para discorrer sobre uma temática e também da revisão autobiográfica, que valoriza histórias pessoais como parte importante do processo, como também a proposição de ressignificação destas narrativas. A pesquisa revelou que o corpo afrodescendente ainda passa por opressões dentro da escola, embora hoje, haja legislação específica e uma adaptação ainda incipiente das escolas para a diminuição destas sequelas. Por outro lado, a pesquisa incita que a valorização de narrativas pessoais certamente pode contribuir para a autoestima de pessoas negras e sua emancipação pessoal e social dentro e fora da escola. Narrativas próprias são importantes para a compreensão de narrativas maiores como as estruturas de poder, ficando evidenciado também que estas "pequenas" histórias são capazes de nos ensinar sobre como lidar com estas estruturas sociais.
\end{abstract}

Palavras-chave: Corpo; Escola; Racismo; Narrativas.

\begin{abstract}
The present study refers to the relationships of the Afro-descendant body with the school, with the aim of understanding how the school can contribute to the process of valuing different bodies in order to fight racism. It is known that racism throughout the history of the formation of the Brazilian people has left great social consequences and with this, it is intended, in addition to denouncing, to propose possibilities for confronting it. As a methodology, the research chose to follow the perspective of narrative review, which seeks references to discuss a theme and also the autobiographical review, which values personal stories as an important part of the process, as well as the proposition of resignification of these narratives. The research revealed that the Afro-descendant body still undergoes oppression within the school, although today, there is specific legislation and an incipient adaptation of schools to reduce these consequences. On the other hand, the research encourages that valuing personal narratives can certainly contribute to the self-esteem of black people and their personal and social emancipation inside and outside school. Own narratives are important for understanding larger narratives such as power structures, and it is also evident that these "small" stories are able to teach us about how to deal with these social structures.
\end{abstract}

Keywords: Body; School; Racism; Narratives.

\section{Resumen}

Este estudio se refiere a las relaciones del cuerpo afrodescendiente con la escuela, con el objetivo de comprender cómo la escuela puede contribuir al proceso de valoración de diferentes cuerpos para combatir el racismo. Se sabe que el racismo a lo largo de la historia de la formación del pueblo brasileño ha dejado grandes consecuencias sociales y con ello, se pretende, además de denunciar, proponer posibilidades para enfrentarlo. Como metodología, la investigación optó por seguir la perspectiva de la revisión narrativa, que busca referencias para discutir un tema y también la revisión autobiográfica, que valora las historias personales como parte importante del proceso, así como la propuesta de resignificación de estas narrativas. La investigación reveló que el cuerpo afrodescendiente aún sufre opresión dentro de 
la escuela, aunque hoy existe una legislación específica y una incipiente adaptación de las escuelas para reducir estas consecuencias. Por otro lado, la investigación alienta que la valoración de las narrativas personales ciertamente puede contribuir a la autoestima de las personas negras y su emancipación personal y social dentro y fuera de la escuela. Las narrativas propias son importantes para comprender narrativas más amplias, como las estructuras de poder, y también es evidente que estas "pequeñas" historias pueden enseñarnos cómo lidiar con estas estructuras sociales.

Palabras clave: Cuerpo; Colegio; Racismo; Narrativas.

\section{Introdução}

O presente estudo é parte dos resultados da pesquisa de mestrado intitulada "aprender com a diversidade: narrativas de um corpo para além da sala de aula” escrita para o Programa de Pós-graduação em Educação - PPGED da Universidade Federal do Piauí - UFPI por Kácio dos Santos Silva e orientada pelo professor PhD Francis Musa Boakari. Ela também é fruto de constantes trocas com o grupo de pesquisa Roda Griô - GEAfro: Gênero, educação e afrodescendência que, desde 2010, procura criar respostas à cultura de silenciamento em torno das discriminações persistentes, particularmente em torno das discriminações raciais e de gênero (Boakari \& Silva, 2020). Esta pesquisa trabalhou com narrativas sobre corpos afrodescendentes e sua relação com processos escolares e não escolares na formação da subjetividade da pessoa afrodescendente no combate ao racismo.

Para isso, a pesquisa se debruçou a analisar quatro categorias presentes nestas narrativas: o corpo, a escola, as relações familiares e a dança. A escolha destas narrativas foi devido à relação pessoal do pesquisador com as categorias escolhidas. Mas neste artigo, trataremos apenas de duas destas categorias: o corpo e a escola, com o objetivo de compreender como a escola pode contribuir no processo de valorização dos diferentes corpos na intenção de combater o racismo.

O corpo deve ser entendido como resultado provisório de diversas pedagogias que o conformam em determinadas épocas e lugares. Ele é marcado e distinguido muito mais pela cultura do que por uma presumível essência natural. O corpo adquire diferentes sentidos no momento em que é investido por um poder regulador que o ajusta em seus menores detalhes, impondo limitações, autorizações e obrigações (Fraga, 2001, p. 63).

Neste sentido, Nóbrega (2005, p.610) ao discutir a necessidade da criação de uma agenda do corpo na educação (a partir da compreensão fenomenológica do corpo, referenciada por Merleau-Ponty, Varela e Maturana) alerta: "Não se trata de incluir o corpo na educação. O corpo já está incluído na educação. Pensar o lugar do corpo na educação significa evidenciar o desafio de nos percebermos como seres corporais". Por outro lado, a tomada de consciência por si só não transforma a realidade das relações com o corpo, ela deve ser acompanhada de atuação, pelo enfrentamento das amarras a que as relações corpo e educação estão submetidas.

O acesso ao conhecimento verdadeiro é negado ao corpo pela lógica cartesiana, na sala de aula multiplica-se o treino mental. O aluno é somente cabeça, permanecendo horas sentado com olhar fixo no professor, à frente a lógica da disposição espacial da sala em fileiras permite olhar seus amigos somente de costas. Estas, como tantas outras construções históricas, resistem a mudanças e adquirem novas roupagens para conservar-lhes a essência (Campos \& Campos, 2006).

Em se tratando da escola, podemos afirmar que este é um dos lugares que mais impõe determinados comportamentos ou modos de ser para os corpos, Gomes (2002) revela que

a escola impõe padrões de currículo, de conhecimento, de comportamentos e também de estética. Para estar dentro da escola é preciso apresentar-se fisicamente dentro de um padrão, uniformizar-se. A exigência de cuidar da aparência é reiterada, e os argumentos para tal nem sempre apresentam um conteúdo racial explícito. Muitas vezes esse conteúdo é mascarado pelo apelo às normas e aos preceitos higienistas. Existe, no interior do espaço escolar, uma determinada representação do que é ser negro, presente nos livros didáticos, nos discursos, nas relações pedagógicas, nos cartazes afixados nos murais da escola, nas relações professor/a e aluno/a e dos alunos/as entre si. Estudos como o de Gonçalves (1985) apontam para que na maioria das vezes a questão racial existe na escola por meio da sua ausência e do seu silenciamento (Gomes, 2002). 
A partir desse pensamento, é importante compreender que quando tratamos do corpo afrodescendente, o mesmo foi excluído da escola por muito tempo, o qual foi proibido de estudar. Diversas legislações e decretos negaram o corpo negro dentro da escola, como revela as diretrizes Curriculares Nacionais (DCNs) para as relações étnico-raciais:

o Brasil, Colônia, Império e República, teve historicamente, no aspecto legal, uma postura ativa e permissiva diante da discriminação e do racismo que atinge a população afro-descendente brasileira até hoje. O Decreto ${ }^{\circ} 1.331$, de 17 de fevereiro de 1854, estabelecia que nas escolas públicas do país não seriam admitidos escravos, e a previsão de instrução para adultos negros dependia da disponibilidade de professores. O Decreto ${ }^{\circ}$ 7.031-A, de 6 de setembro de 1878 , estabelecia que os negros só podiam estudar no período noturno e diversas estratégias foram montadas no sentido de impedir o acesso pleno dessa população aos bancos escolares (Brasil, 2004).

Sobre todas estas questões então, as DCN's indicam que a educação brasileira precisa reconhecer “a adoção de políticas educacionais e de estratégias pedagógicas de valorização da diversidade, a fim de superar a desigualdade étnico-racial presente na educação escolar brasileira, nos diferentes níveis de ensino" (Brasil, 2004).

Esta legislação juntamente com uma sociedade engajada em combater o racismo justificam a necessidade de pesquisas como esta, na intenção de construirmos uma sociedade emancipada e com a promoção de justiça social para toda a sociedade brasileira. Dessa forma, faz-se necessário pensar sobre o papel da escola nesse processo de construção da subjetividade do sujeito, pois é na escola, onde a criança começa a ter contato com outras crianças e a perceber a diferença entre as mesmas.

\section{Metodologia}

Assim, a metodologia deste artigo, trata-se da utilização de dois métodos: a revisão narrativa de literatura e a escrita autobiográfica. De acordo com Cordeiro et al., (2007) "a revisão da literatura narrativa ou tradicional, quando comparada à revisão sistemática, apresenta uma temática mais aberta; dificilmente parte de uma questão específica bem definida, não exigindo um protocolo rígido para sua confecção". Já o método autobiográfico é detalhado por Abrahão (2003) como uma metodologia em que o pesquisador conscientemente adota uma tradição em pesquisa que reconhece ser a realidade social multifacetária, socialmente construída por seres humanos que vivenciam a experiência de modo holístico e integrado, em que as pessoas estão em constante processo de autoconhecimento.

A importância de realizar uma pesquisa autobiográfica é uma forma não só de evidenciar uma pequena grande história, mas também de visibilizar corpos outrora subalternizados que muitas vezes foram silenciados reafirmando assim, que todo corpo não só pode falar, mas também possui lugar de fala. Para Ribeiro (2019)

todas as pessoas possuem lugar de fala, pois estamos falando de localização social. E, partir disso, é possível debater e refletir criticamente sobre os mais variados temas presentes na sociedade. O fundamental é que indivíduos pertencentes ao grupo social privilegiado em termos de locus social consigam enxergar as hierarquias produzidas a partir desse lugar, e como esse lugar impacta diretamente a constituição dos lugares de grupos subalternizados (Ribeiro, 2019, Pág. 85).

Para dialogar com a pesquisa também foi adotado o conceito de narrativa relevada por Benjamin (2002), que traz a história de sua infância, não para falar na perspectiva autobiográfica, mas para promover diálogo com o contexto social daquele lugar e tempo. E a de astúcia defendida por Michel de Certeau que propõe uma inversão na forma de interpretar práticas culturais ao reinventar o cotidiano dentro de um espaço e tempo (Duran, 2007).

Assim, é importante entender que a pesquisa narrativa pode partir de qualquer tempo e lugar, perpassando não só pela trajetória de vida de uma única pessoa, mas pela de muitas outras que apresentem semelhanças em seu modo de existir com suas características, emoções, pulsões e escolhas.

\section{Resultados e Discussão}


Os resultados desta pesquisa apresentam-se divididos em três pontos distintos: no primeiro, o corpo afrodescendente, no segundo, a escola, que são as polifonias no conceito de Bakhtin (2003), e depois, a dialogia que é quando essas categorias conversam entre si.

\subsection{O Corpo afrodescendente}

Para tratar da primeira categoria, no caso o corpo afrodescendente, utilizou-se alguns referenciais para o reconhecimento da negritude, como em Sousa, (1983. Pág. 17) que revela que para um melhor reconhecimento da negritude o primeiro passo é o despertar para o que a autora chama de "tornar-se negro", pois "uma das formas de exercer a autonomia é possuir um discurso sobre si mesmo. Discurso que se faz muito mais significativo quanto mais fundamentado no conhecimento concreto da realidade".

Esse processo (tornar-se negro) embora pareça estar dado, não é tão simples para muitas pessoas afrodescendentes assumirem para si este discurso, haja vista que nossas narrativas pessoais na maior parte das vezes são atravessados por relações de poder destacada da seguinte forma por Foucault (2002): "suponho que em toda a sociedade a produção do discurso é simultaneamente controlada, seleccionada, organizada e redistribuída por um certo número de procedimentos que têm por papel exorcizar-lhe os poderes e os perigos, refrear-lhe o acontecimento aleatório, disfarçar a sua pesada, temível materialidade".

Assim, cada sujeito pode perceber que boa parte da sua formação de subjetividade é constantemente elaborada em vários espaços e tempos, em que este corpo negro é um marcador neste processo, devido a historicidade de subalternidade que estes corpos foram submetidos no decorrer da história.

Uma outra questão nesse processo de demora de autorreconhecimento desse corpo negro é a falsa e difundida ideia de democracia racial, que segundo Domingues (2005) "significa um sistema racial desprovido de qualquer barreira legal ou institucional para a igualdade racial, e em certa medida, um sistema racial desprovido de qualquer manifestação de preconceito ou discriminação". O que contribui para o não reconhecimento do racismo e a consequente falta de propostas de combate do mesmo.

Assim, o reconhecimento deste corpo afrodescendente muitas vezes é um processo demorado e muitas vezes só acontece quando o sujeito se depara com alguma situação racista que o faz perceber a discriminação racial do outro. Muitas vezes este processo de autorreconhecimento se dá também quando uma pessoa afrodescendente passa por experiências estéticas que o levam a esse processo. Sobre isto, Nilma Lino Gomes (2002) revela que:

para o/a adolescente negro/a, a insatisfação com a imagem, com o padrão estético, com a textura do cabelo é mais do que uma experiência comum dos que vivem esse ciclo da vida. Essas experiências são acrescidas do aspecto racial, o qual tem na cor da pele e no cabelo os seus principais representantes. Tais sinais diacríticos assumem um lugar diferente e de destaque no processo identitário de negros e brancos brasileiros. A rejeição do cabelo pode levar a uma sensação de inferioridade e de baixa autoestima contra a qual faz-se necessária a construção de outras estratégias, diferentes daquelas usadas durante a infância e aprendidas em família (Gomes, 2002, pág. 47).

Adequar-se a um padrão de beleza tem sido uma grande questão da sociedade contemporânea. A partir de uma suposta valorização do corpo, este passou a ser um lugar de exercício de poder. Sobre isso, a a filósofa Viviane Mosé (2018) nos relata que:

- É comum a gente dizer que nós vivemos um culto ao corpo, não é isso? mas isso é completamente irreal, nós não só não vivemos um culto ao corpo, como nós desvalorizamos o corpo. O que é isso que a gente valoriza tanto que a gente chama de corpo, e que eu tô dizendo que não é corpo. Nós valorizamos a imagem do corpo, nós valorizamos o photoshop especialmente, porque aquela imagem de corpo que aparece pra gente não é o corpo que foi fotografado (Mosé, 2018). 
Esse corpo torna-se manipulado então a partir de um ideal de branquitude e que para Gomes (2003) "é um símbolo explorado nas relações de poder e de dominação para classificar e hierarquizar grupos diferentes. O corpo é uma linguagem e a cultura escolheu algumas de suas partes como principais veículos de comunicação".

Não é intenção desta pesquisa dizer que partes do corpo não podem ser manipuladas pela tecnologia, e que este corpo não pode ser ressignificado, mudado. A discussão é sobre pensar se este processo está sendo feito em algum nível de consciência ou apenas esteja sendo refém de um único padrão de beleza, nesse caso, o padrão eurocentrado.

Assim, podemos entender o corpo afrodescendente como o corpo com características bem peculiares, em sua maioria definidas pelo tom de pele, traços do rosto e cabelos, onde este último é um dos marcadores que mais podem passar por manipulações e descaracterizações de sua origem. Por muito tempo, e ainda muito presente nos dias de hoje, o cabelo crespo sofreu/sofre muitas discriminações e carrega consigo uma carga de representações ainda muito fortes e que tem atravessado séculos de colonização, onde a partir do século XIX para Damatta, (1987) “o racismo aparece na sua forma acabada, como um instrumento do imperialismo e como uma justificativa 'natural' para a supremacia dos povos da Europa Ocidental sobre o resto do mundo".

Dentre os diversos traços do corpo, o cabelo entra como um forte marcador desse processo. Quintão (2013) destaca que "desde pelo menos o século XIX, o cabelo liso do branco europeu vem sendo associado a características positivas - ao cabelo 'bom' - enquanto o cabelo crespo do negro vem sendo associado a características negativas - ao cabelo 'ruim' - categorizando crespos como inferiores a lisos" (Quintão, 2013).

Neste sentido, "livrar-se" do cabelo crespo seria deixar de carregar toda uma carga histórica que, no caso do Brasil, vem do processo escravocrata que perdurou durante séculos, e que mesmo depois de passado este processo, continuou perpetuado, pela falta de políticas públicas voltadas para as futuras gerações.

\subsection{O espaço escolar}

Nesta segunda categoria a pesquisa destaca um dos lugares mais marcantes da vida de uma pessoa que é o espaço escolar. É nele que o contato com o outro se intensifica, e assim começa-se muito cedo a entender quem se é. Este processo se dá através da consciência de si, a partir de uma produção da autoimagem e, consequentemente da autoestima, a partir das relações que construímos com o outro, sejam alunos, professores, vigia, merendeira, secretária ou a escola em si.

Essa produção de autoimagem está fortemente pautada naquilo que somos enquanto corpos fisiológicos. Ou seja, nosso cabelo, tom de pele, estatura, tamanho da cabeça, por exemplo. Associado a isso, todo o aporte cultural que nos acompanha, como o nome, a rua onde moramos, a mochila que carregamos ou o cheiro dos nossos corpos, também são comumente utilizados para nos definir, nos rotular, e por vezes, nos discriminar dentro do espaço escolar. As produções das imagens para Bittencourt (2012, p.22)

surgem por auto-organização de reverberações de informações entre diferentes níveis de descrição do corpo. [...] Tratase de um procedimento variável e dinâmico, já que cada imagem singulariza um tipo de conexão ocorrida em um determinado momento. Como se trata de um procedimento que se auto-organiza na ação de percepção, o que significa a ocorrência de movimento no corpo, as imagens se encontram implicadas em acordos constantes (Bittencourt, 2012, p.22).

Logo, na escola os traços fisiológicos e comportamentais produzem imagens que, dentro de um processo cultural podem ser utilizadas para processos de discriminações que, Segundo Laraia (2001, pág. 67), essa "nossa herança cultural, desenvolvida através de inúmeras gerações, sempre nos condicionou a reagir depreciativamente em relação ao comportamento daqueles que agem fora dos padrões aceitos pela maioria da comunidade". 
Embora pense que, quando o autor supracitado explica que somos condicionados a reagir depreciativamente aos que não estão "de acordo com a maioria da comunidade", como então nós, sujeitos da escola, podemos reorganizar essa forma de pensar sobre o diferente? Como o aluno que se encontra esteticamente ou socialmente fora do padrão da maioria dos alunos daquele espaço escolar, ao invés de ser subalternizado seja potencializado? A escola pode então, na prática ser um lugar do exercício da tolerância e do respeito às diversidades?

Para tal, é necessário partir do entendimento que, além de perceber a escola como apenas um processo de ensinoaprendizagem, ela é um locus de processos relacionais que contribuirão fortemente para a elaboração de subjetividade de cada um. Mosquera e Stobäus (2008) explicam que o entendimento da afetividade e da subjetividade estão diretamente relacionadas com o bom desenvolvimento cognitivo, pois elas estão intrinsecamente conectadas. Para Machado, Gonçalves e Almeida (2011, p. 79),

estas diferenças culturais, se vistas como diversidade, trazem o benefício de permitir que o "meu mundo" possa ser ressignificado a partir do que esta sociedade passa a conhecer da sociedade do outro. É neste aspecto que o sentido de alteridade empresta importante papel à compreensão da diversidade (Machado, Gonçalves \& Almeida, 2011, p. 79).

Assim, a escola precisa ser pensada como determinado lócus, que além da produção de conhecimento produz subjetividades. É nela que construiremos ou desconstruiremos estereótipos e relações mais igualitárias, partindo de um pressuposto, não de negar as diferenças, mas na intenção de valorizá-las combatendo as práticas discriminatórias. É o ato performativo, ou seja, a própria existência do corpo naquele contexto que contribuirá exaustivamente para a construção dessa autoimagem no espaço escolar. Para Padilha e Machado (2019), este processo contribui para refletir sobre práticas educativas, sendo possível contribuir assim com o processo de resistência ao discurso hegemônico através do reconhecimento social e científico de pedagogias insurgentes, que subvertam espaços de poder e cooperem na construção de uma sociedade mais justa e igualitária na ótica cognitiva e epistêmica.

\subsection{A escola e as narrativas afrodescendentes}

Nesse contexto de discussão sobre o corpo, podemos pensar sobre este corpo afrodescendente que muitas vezes é silenciado e/ou discriminado dentro da escola que urge por reformas e mudanças de posturas que dêem voz e significado, para além das representações simbólicas que o corpo negro tem tido no decorrer da história. Gomes (2002) afirma que:

o estudo sobre as representações do corpo negro no cotidiano escolar poderá ser uma contribuição não só para o desvelamento do preconceito e da discriminação racial na escola, como também poderá ajudar-nos a construir estratégias pedagógicas alternativas que nos possibilitem compreender a importância do corpo na construção da identidade negra de alunos/as, professores/as negros, mestiços e brancos, e como esses fatores interferem nas relações estabelecidas entre esses diferentes sujeitos no ambiente escolar. Na escola, não só aprendemos a reproduzir as representações negativas sobre o cabelo crespo e o corpo negro; podemos também aprender a superá-las (Gomes, 2002).

Dessa forma, Campos e Campos (2006) reafirma que este empoderamento pela linguagem corporal e a ressignificação do corpo no processo de ensino-aprendizagem não deve acontecer somente para o aluno com relação ao seu corpo, mas, também para o professor. Ele deve ser, sobretudo, profundamente transformador para o professor, porque na realidade somente poderemos libertar nossos alunos de um corpo adestrado quando nos libertamos também de nossas amarras corporais.

Nesse contexto, podemos pensar o corpo afrodescendente, que ao longo de nossa história de colonização foi desprestigiado em favor da matriz eurocêntrica, através do processo de escravidão e perpetuado pela escassez de políticas públicas de reparação e diminuição da desigualdade sócio racial. Assim, podemos destacar que alguns conteúdos, acabam precisando da implementação de leis para contemplá-los e garantir à população uma formação mais inclusiva e preocupada com 
as realidades do país. Dentre estas, podemos destacar a lei $\mathrm{N}^{\circ}$ 10.639/03 que regulamenta o ensino das culturas afro-brasileira e africana na educação básica.

Neste contexto, destaco que, no ensino da cultura afro-brasileira, apesar de ter sido regulamentado, as práticas educacionais provenientes destas tradições, ainda é pouco valorizada e efetivada nos espaços institucionalizados, a exemplo da escola, justificando a formulação de materiais pedagógicos que efetivem o ensino deste legado que está entranhado em muitas de nossas manifestações culturais. Assim sendo, Petit (2015) afirma:

No Brasil de hoje, em que se conquistou uma lei que institui pela primeira vez, o ensino da história e da cultura africana e afro-brasileira nas escolas (10.639/03), torna-se um grande desafio fazer da cosmovisão africana e da tradição oral, conteúdos curriculares, uma vez que os programas escolares têm sido, até agora, sempre eurocêntricos, baseados em princípios até mesmo antagônicos aos das culturas negras (Petit, 2015, p.110).

Dessa forma, faz-se necessário desenvolver materiais que valorizem, através de práticas pedagógicas diferenciadas, conteúdos que possam falar sobre a contribuição das culturas africana e afrodescendentes dentro das escolas, onde o estudo sobre a identidade negra presentes nos processos educativos escolares e não escolares, poderá apontar para outros caminhos além da denúncia da reprodução de preconceitos e estereótipos. Para Moreira, (2019) as ações afirmativas na escola são importantes para evidenciar de forma positiva experiências vividas que podem ser ressignificadas.

É preciso pensar que todas essas relações construídas com o corpo, tanto no espaço físico da sala de aula, quanto nos outros espaços da escola com os seus atores sociais são processos experienciais entre ser e ambiente, com influência de um no outro, gerando assim um processo educativo. Dewey (2011) destaca esse processo de interação (corpo e ambiente), como possibilidade para reconstrução e reorganização da experiência, para promover assim um processo educativo futuro, através de uma experiência nova.

Positivar estas narrativas de corpos afrodescendentes dentro da escola certamente contribuirá para a emancipação pessoal de cada um, o que para Mosquera et al (2006, p. 4) essas experiências vão assim, nos fazendo elaborar um autoconceito de si pautado em dois processos: no desenvolvimento da autoimagem, como um reconhecimento que fazemos de nós mesmos; e, da autoestima, sobre quando gostamos de nós mesmos e que as duas estão intimamente ligadas ao processo identitário, contribuindo para a formação da personalidade do indivíduo.

\section{Conclusão}

O objetivo desta pesquisa não foi denunciar que corpos afrodescendentes são vítimas de uma sociedade racista. Isto já está dado. Mas sim de revelar como estes processos podem ser subvertidos. A pesquisa revelou que este processo pode ser dar de duas formas: a primeira é através das narrativas pessoais que podem denunciar as opressões que este corpo negro pode estar submetido. A segunda é através de como a escola pode repensar ações para contribuir com práticas antirracistas, especialmente através do reconhecimento e da valorização de narrativas positivadoras do corpo afrodescendente.

O processo de escolarização talvez seja um dos mais controversos momentos da vida de uma pessoa. Para aquelas que estão dentro de um padrão normativo, a escola certamente potencializará este sujeito, uma vez que a escola ainda possui um padrão de ensino aprendizagem pautado em um determinado rendimento do aluno. E ela assim o faz através da domesticação da linguagem que perpassa não só pela língua, mas pelo corpo, pelos costumes, e pelos contextos de cada um. Nesse processo muitas vezes a escola ignora as diversidades e quando as respeita, só o faz para uma satisfação mínima com a sociedade.

Por outro lado, toda vez que um corpo negro adentrar dentro de um espaço escolar, a escola se modificará, seja pela fricção que esta presença causará ou pela força molar de resistência em ocupar os espaços que por direito legislativo e/ou de vida são de todas as pessoas. Hoje, pessoas afrodescendentes são muitas dentro dos processos educacionais, desde as creches até a 
universidade pública, sendo cotistas ou não, mas ocupando espaços que são seus de direito. Comemorar cada conquista e registrálas através de pesquisas acadêmicas como esta é uma outra forma de combater as práticas racistas.

Sugerem-se que cada vez mais pesquisas que valorizem narrativas próprias de pessoas afrodescendentes sejam potencializadas através de estudos interseccionais com categorias como classe econômica, gênero e territorialidade, haja vista que o Brasil é um país socialmente desigual e extenso territorialmente.

\section{Referências}

Abrahão, M. H. M. B. (2003). Memoria, narrativas e pesquisa autobiográfica. História da Educação, ASPHE/FaE/UFpel, (14), 79-95.

Bakhtin, M. M. (2003). Estética da criação verbal. Introdução e tradução por Paulo Bezerra. Editora Martins Fontes.

Benjamin, W. (2002). Reflexões sobre a criança, o brinquedo e a educação. Tradução: Marcos Vinícius Mazzari. Duas cidades.

Bittencourt, A. (2012). Imagens como acontecimentos: dispositivos do corpo, dispositivos da dança. EDFUBA.

Boakari, F. M., \& Silva, F. B. (2020). Como narrativas cotidianas, o que ensinam os Congeafros? Anais do VII Congresso Internacional sobre Gênero, Educação e Afrodescendência - VII CONGEAfro (Brasil/Moçambique): Afrodescendentes em narrativas cotidianas. Teresina - PI.

Brasil (2004). Ministério da Educação. Diretrizes Curriculares Nacionais para a Educação das Relações Étnico-Raciais e para o Ensino de História e Cultura Afro-Brasileira e Africana.

Campos, P. F. M., Campos, V. (2006). Escola: espaço de convivência. Relatório - Estágio Supervisionado em Pedagogia. Universidade de Brasília, Faculdade de Educação.

Cordeiro et al. (2007). Revisão sistemática: uma revisão narrativa. Comunicação Científica. Rev. Col. Bras. Cir. 34 (6).

Damatta, R. (1987). "Digressão: a fábula das três raças." Relativizando: Uma introdução à antropologia social. 1, J. Olympio.

Dewey, J. (2011). Experiência e educação. Tradução de Renata Gaspar. Vozes.

Domingues, P. (2005). O mito da democracia racial e a mestiçagem no Brasil (1889-1930). Diálogos latino-americanos, (010), Revistas científicas de América Latina y el Caribe, España e Portugal. Universidad Autonoma del Estado de México.

Duran, M. C. G. (2007). Ensaio sobre a contribuição de Michel de Certeau à pesquisa em formação de professores e o trabalho docente. Educação e linguagem, (15), 117-137.

Foucault, M. (2002). A ordem do discurso. Loyola.

Fraga, A. B. (2001). Anatomias emergentes e o bug muscular: pedagogias do corpo no limiar do século XXI. In: SOARES, C. L. (Org.). Corpo e História. Campinas: Autores Associados, 61-77.

Gomes, N. L. (2002) Trajetórias Escolares, Corpo Negro E Cabelo Crespo: Reprodução De Estereótipos Ou Ressignificação Cultural?. Revista Brasileira de Educação, (21), 40-51.

Gomes, N. L. (2003). Educação, identidade negra e formação de professores/as: um olhar sobre o corpo negro e o cabelo crespo. Educação e Pesquisa, 29(1), $167-182$.

Laraia, R. B. (2001), Cultura: um conceito antropológico (14a ed.), Jorge "Zahar Ed.

Machado M. S.C., Gonçalves, F. W. A. S. \& Almeida, J. D. (2011). A diversidade: diferenças, cultura, bullying e escola em foco. In: BONFIM, Maria do Carmo Alves do et al. Gênero e diversidade na escola. EDUFPI, 346p.

Moreira, M. S. (2019). Identidade afrodescendente: uma construção da história brasileira. Anais do VI Congresso Internacional sobre Gênero, Educação e Afrodescendência - VI CONGEAfro. Políticas públicas e diversidades: quem precisa de identidade? Teresina - PI

Mosé, V. (2018). O que pode o corpo?| Dani Lima. Youtube.

Mosquera et al. (2006). Universidade: auto-imagem, auto-estima e auto-realização. UNIrevista, 1(2), 1-13.

Mosquera, J. J. M., Stobäus, C. D. (2008) Auto-imagem, auto-estima e auto-realização na universidade. In: Enricone, D. (Org.). A docência na educação superior: sete olhares. (2a ed.), EDIPUCRS.

Nóbrega, T. P. (2005). Qual o lugar do corpo na educação? Notas sobre conhecimento, processos cognitivos e currículo. Educ. Soc. 26(91).

Padilha, G. S. S., \& Machado, R. N. S. (2019). Pedagogia afrocentrada em práticas educativas de professoras afrodescendentes universitárias. Estudos sobre Educação. Presidente Prudente - SP, 30 (1), 188-203.

Petit, S. H. (2015). Pretagogia: pertencimento, corpo-dança afroancestral e tradição oral - contribuições do legado africano para a implementação da lei 6.639/03. edUECE. 
Research, Society and Development, v. 10, n. 12, e186101219998, 2021

(CC BY 4.0) | ISSN 2525-3409 | DOI: http://dx.doi.org/10.33448/rsd-v10i12.19998

Quintão, A. M. P. (2013). O que ela tem na cabeça?: Um estudo sobre o cabelo como performance identitária. Dissertação de mestrado. Universidade Federal Fluminense, Instituto de Ciências Humanas e Filosofia, Departamento de Antropologia.

Ribeiro, D. (2019). O que é lugar de fala? Feminismos plurais. Sueli Carneiro. Pólen.

Souza, N. S. (1983). Tornar-se negro: as vicissitudes da identidade do negro brasileiro em ascenção social. Editora Graal. Coleção tendências. 4. 